\title{
EVALUATION OF TOXIC POTENTIALS OF Cola millenii K. Schum SEED AND PULP FLOUR IN FOOD FORMULATIONS
}

\author{
Adegoke Aanuoluwa Eunice ${ }^{2}$, Bello Muibatu O², Arotayo Rafat Aduke², Adegbola Peter \\ Ifeoluwa ${ }^{1 \bowtie}$ \\ ${ }^{I}$ Department of Biochemistry, Faculty of Basic Medical Sciences, Ladoke Akintola University of Technology \\ ${ }^{2}$ Department of Pure and Applied Chemistry, Faculty of Pure and Applied Sciences, Ladoke Akintola University \\ of Technology \\ هiadegbola27@lautech.edu.ng; useablevesselofgod@gmail.com \\ https://doi.org/10.34302/crpifst/2020.12.5.11 \\ Article history: \\ Received: \\ 28 August 2020 \\ Accepted: \\ 25 December 2020 \\ Keywords, \\ Food safety; \\ Toxicity; \\ Cola milleni; \\ Food; \\ Rats.

\begin{abstract}
Different parts of Cola millenii have been used in traditional medicine and available information in the literature has highlighted some nutritional potentials of Cola millenii seed and pulp. Previous studies on the toxicity of the seed were conducted on the extracts and conflicting evidences were obtained. Therefore, this study assesses the health risk of consuming Cola millenii seed and pulp flour in Wistar Albino rats.

The result obtained showed insignificant $(\mathrm{p}>0.05)$ difference in the organ weight of rats across the groups. Feeding of animals with the whole seed, pulp, and defatted seed flour showed no toxic effects on the food and water intake. Significant $(\mathrm{p}<0.05)$ increase was observed in the AST activity of group fed with whole seed and defatted seed flour while no significant ( $>0.05)$ difference was observed in the ALT and GGT activity across the groups. Creatinine concentration decreased significantly $(p<0.05)$ in the group fed with the defatted seed flour while urea concentration decreased significantly $(p<0.05)$ in the group fed with the whole seed flour. Degenerative changes indicated by inflammation, necrosis and fibrosis were observed in the liver of group fed with the whole seed flour as well as in the kidney of groups fed with whole seed, defatted seed, and pulp of $C$. millenii. The result of this study showed that $C$. millenii seed might be slightly toxic. Therefore, there is a need for caution in the use of C. millenii as food.
\end{abstract}

\section{Introduction}

Plants remain a widely accepted component of Western diets and several health benefits are attributed to the consumption of plant foods (Deanna, 2019). Due to the increasing demand on valuable foods with sufficient nutrient, efforts are being made to boost food production with interest focused on the possibility of exploring the less familiar plants of the wild (Anhwange et al., 2004). The tropical Africa sub-region is home to many potentially valuable fruit species of which many are yet to be fully exploited. Therefore, there is need to promote crop and food diversifications to include neglected and underutilized species that are readily affordable and accessible to the rural and urban dwellers and most times can withstand the stresses linked to climate change (Bello et al., 2008). Although some of these plants that grow in the wild are gaining attention among 
researchers. One of these is Cola millenii K. Schum, commonly known as monkey kola. The fruit is bright red in a stellate cluster and its seed is covered with a fibrous coat with an edible kernel. The pulp has a varying characteristics sweetness which makes it useful as snack while seed is mostly appreciated for its therapeutic uses (Orisakeye and Ojo, 2013; Borokini et al., 2014).

The nutritional potentials of $C$. millenii showed that the seed contain sufficient amount of carbohydrate, protein and fibre as well as essential minerals required for general wellbeing (Ibironke et al. (2013). In addition, phytochemical studies on the seed and pulp showed that it has medicinal potentials as it contains important phytochemicals such as saponins, terpenoids, tannins and alkaloids (Giwa et al., 2012). Furthermore, the seed and pulp possess strong antimicrobial and antioxidant activity (Adeniyi et al., 2004; Orisakeye et al., 2013; Borokini et al., 2014). Therefore, C. milleni is an important medicinal plant with valuable nutritional usefulness.

Although, plant foods contain essential nutritional constituents, there are increasing concerns because of their safety when consumed (Suzanne et al., 2011). Currently, most toxicity studies conducted on $C$. milleni were performed on the seed and leaf extracts and a range of potential contraindications such as hepatic and renal toxicity have been identified (Oyemitan et al., 2016; Itoandon et al., 2016). Ubon et al. (2017) on the contrary reported that the ethanolic extract of the seed is non-cytotoxic, non-hepatotoxic and non-cardiotoxic. Therefore, this conflicting evidences need to be investigated. Hence, the study assessed the health risk of consumption of $C$. millenii seed and pulp flour in Wistar Albino rats.

\section{Methods}

\subsection{Sample collection}

Ripe monkey cola fruits were collected in February 2019 from (Omo Odo Agba Area, Near Baba Kekere, Osogbo) Latitude 7.762216, longtitude (4.579217) Oke-Baale area, Osogbo local government in Osun State, Nigeria.

\subsection{Sample preparation}

The ripe fruits were washed and left to dry off at room temperature. The fruit's endocarp was cut open with the use of a knife and then the clustered seeds were removed. The pulp (mesocarp) was removed from the seed itself and was left to air-dry separately at room temperature. After drying, the seeds and pulp were ground separately using a using a blender (Power Deluxe CB $8231 \mathrm{~N}$ model) until a fine homogenous sample was obtained and the ground sample was kept an air-tight container. A portion of the ground seed sample was defatted by weighing into a filter paper and inserted into the thimble of a Soxhlet apparatus. $200 \mathrm{ml}$ of $\mathrm{n}$ hexane was measured into the round bottom flask of the soxhlet setup. The condenser was coupled and the setup was heated to reflux using a heating mantle. The oil sample was extracted continuously for 4 hours. The cake was then placed in oven at less than $60^{\circ} \mathrm{C}$ for 2 hours until uniform weight was obtained. The deffated seed (seed cake) was then kept in an air-tight container for animal feeding.

Commercial stock rat diet was obtained from Glory veterinary, Oritanaira Area, Ogbomoso, Oyo State. Diets were prepared by mixing $95 \%$ of the commercial diet with $5 \%$ of pulp, cake and seed of $C$. milleni separately every day (Datta et al., 2011).

\subsection{Experimental Design}

Adult Swiss male Albino rats (120-180g) used in this study were divided into 4 groups of 5 animals. Group A received the normal commercial diet, Group B received feed mixed with $5 \%$ pulp flour, Group $\mathrm{C}$ received diet mixed with $5 \%$ defatted seed flour while Group $\mathrm{D}$ received diet mixed with $5 \%$ seed flour. The animals were maintained in Basket Cages with wood shave as beddings and kept under standard condition of relative humidity and temperature. Standard protocol on animal handling and care were followed throughout the study whereas approval and permission for animal use were obtained prior to the commencement of the study. 


\subsection{Acute Toxicity Study}

After grouping of animals, they were fed with diet containing $5 \%$ of $C$. milleni seed, defatted seed, and pulp respectively for 21 days. Daily food and water intake and weekly body weights were monitored (Datta et al., 2011). At the end of the 21 days of experiment, animals were fasted overnight and sacrificed by cervical dislocation. The blood was collected via heart puncture into plane sterile bottles while the liver and kidney were harvested and fixed in formalin buffer for histopathological analyses. Blood sample was allowed to clot and then centrifuge at $4000 \mathrm{rpm}$ for 10 minutes. The serum was then separated and used for further biochemical studies.

\subsubsection{Liver and renal function Analysis}

All biochemical analysis Aspartate Amino Transferase (AST), Alanine Amino Transferase (ALT), Gamma Glutamyl Transferase (GGT), Urea and Creatinine)were performed with Fortress Assay Kit, Fortress Diagnostics Limited, Unit 2C Antrim Technology Park, Antrim, BT41 1QS (United Kingdom) following the standard procedure in the manufacturer guide.

2.4.1.1 Estimation of AST, ALT and GGT activities

The AST and ALT activity was determined by the method described by Tietz, (1995). The AST activity was estimated using the equation, AST activity $=\Delta \mathrm{A} / \mathrm{min} \times 1908$.

While the ALT activity was estimated using the equation, ALT activity $=\Delta \mathrm{A} / \min \times 1746$. GGT activity on the other hand was determined by the method of Szasz, (1976). Its activity was estimated using the equation,

GGT $(\mathrm{U} / \mathrm{L})=1158 \times \Delta \mathrm{A} 405 \mathrm{~nm} / \mathrm{min}$ where $\Delta \mathrm{A} 405 \mathrm{~nm} / \mathrm{min}$ is the change in absorbance

2.4.1.2 Determination of Serum creatinine and Urea concentration

The serum creatinine concentration was determined by the method of Tietz, (1995). While the serum urea concentration was determined by the method described by Fawcett and Scott, (1962). The serum creatinine concentration was estimated using the equation,

Serum
$\frac{\Delta \text { abs sample }}{\Delta \text { abs standard }} \times 177$

Urea concentration was estimated using the equation,

Serum urea concentration $=\frac{\Delta \text { abs sample }}{\Delta \text { abs standard }} \times$ concentration of standard

\subsubsection{Histological Analysis}

The histo-pathological analysis was performed by the hematoxylin and eosin staining (Pearse, 1980). Firstly, the samples were dehydrated through ascending grades of alcohol, cleared in xylene, and then impregnated in paraffin wax of melting point between $55^{\circ} \mathrm{C}$ $56^{\circ} \mathrm{C}$ for infiltration. Tissue sects were mounted on slides and then stained with hematoxylin and eosin $(\mathrm{H} \& \mathrm{E})$. The stained tissues were then observed under microscope.

\subsection{Statistical Analysis}

Data were expressed as mean \pm SEM and analyzed by One-way Analysis of Variance (ANOVA) using Statistical Package for Social Science (SPSS) 21.0. The level of significance was determined at $95 \%$ confident level and separation between mean was determined by Duncan multiple test.

\section{Results and Discussions}

\subsection{Results}

\subsubsection{Acute toxicity of Cola milleni} Seed, Pulp, and Cake on Albino Rats

Table 1 showed the weekly food and water intake of rats fed with the seed, pulp, defatted seed, and commercial diet. Incorporation of $5 \%$ of seed sample showed no effects on the food intake of the treatment groups. The animals showed comparable food and water intake with the control (commercial diet). Figure 1 showed the body weight gain of rats during the period of study. The result showed total body weight increase across the groups. Feeding of the animals with C. milleni had no negative impact on the growth and body weight. In table 2 , the 
effects of feeding the experimental animals with C. milleni on the weight of organs were recorded. No significant variation was observed in the organ to body weight ratio of the animals fed with seed, defatted seed, and pulp. Only in the spleen to body-weight ratio was lower ratio obtained in the treated groups compared with the control.

Table 1. Weekly food and water intake of Albino Rats fed with C. milleni

\begin{tabular}{|l|l|l|l|l|l|l|}
\hline \multirow{2}{*}{ Groups } & \multicolumn{5}{|c|}{ Weekly Food and Water Intake of Rats } \\
\cline { 2 - 7 } & \multicolumn{2}{|c|}{ Week 1 } & \multicolumn{2}{c|}{ Week 2 } & \multicolumn{2}{c|}{ Week 3 } \\
\cline { 2 - 7 } & Food $(\mathrm{g})$ & Water $(\mathrm{ml})$ & Food $(\mathrm{g})$ & Water $(\mathrm{ml})$ & Food $(\mathrm{g})$ & Water $(\mathrm{ml})$ \\
\hline Control & $86.33 \pm 6.33$ & $75.33 \pm 17.76$ & $92.57 \pm 3.39$ & $84.29 \pm 7.75$ & $77.57 \pm 1.56$ & $88.57 \pm 8.84$ \\
\hline Pulp & $96.67 \pm 0.61$ & $71.17 \pm 10.56$ & $98.29 \pm 0.64$ & $85.71 \pm 4.68$ & $93.43 \pm 1.29$ & $98.57 \pm 19.33$ \\
\hline Defatted seed & $87.50 \pm 2.59$ & $98.33 \pm 16.10$ & $93.71 \pm 1.36$ & $88.00 \pm 10.83$ & $89.86 \pm 3.14$ & $89.25 \pm 6.21$ \\
\hline Seed & $87.33 \pm 3.00$ & $79.00 \pm 17.05$ & $90.14 \pm 2.41$ & $94.43 \pm 8.55$ & $93.71 \pm 1.23$ & $112.86 \pm 10.17$ \\
\hline
\end{tabular}

Values were expressed as mean \pm SEM

Table 2. Organ to weight ratio of Albino Rats fed with seed and pulp of C. milleni

\begin{tabular}{|c|c|l|l|c|}
\hline \multirow{2}{*}{ Groups } & \multicolumn{4}{|c|}{ Organ to weight ratio } \\
\cline { 2 - 5 } & Liver & Kidney & Heart & Spleen \\
\hline Control & 0.04 & 0.006 & 0.004 & 0.007 \\
\hline Pulp & 0.03 & 0.004 & 0.003 & 0.004 \\
\hline Defatted seed & 0.03 & 0.007 & 0.004 & 0.004 \\
\hline Seed & 0.03 & 0.005 & 0.003 & 0.004 \\
\hline
\end{tabular}

Organ weight/Weight of animals at week 3 (Sample size, 5)

Table 3. Liver function enzymes in Albino Rats fed with C. milleni

\begin{tabular}{|l|l|l|l|}
\hline \multirow{2}{*}{ Groups } & \multicolumn{3}{|c|}{ Liver Function Markers (U/L) } \\
\cline { 2 - 4 } & AST & ALT & GGT \\
\hline Control & $43.52 \pm 5.69^{\mathrm{a}}$ & $28.52 \pm 3.51^{\mathrm{a}}$ & $2.53 \pm 0.43^{\mathrm{a}}$ \\
\hline Pulp & $56.78 \pm 2.46^{\mathrm{ab}}$ & $32.26 \pm 2.16^{\mathrm{a}}$ & $1.89 \pm 0.25^{\mathrm{a}}$ \\
\hline Defatted seed & $74.89 \pm 3.95^{\mathrm{b}}$ & $26.15 \pm 1.61^{\mathrm{a}}$ & $1.56 \pm 0.29^{\mathrm{a}}$ \\
\hline Seed & $65.83 \pm 7.73^{\mathrm{b}}$ & $27.54 \pm 2.79^{\mathrm{a}}$ & $1.66 \pm 0.17^{\mathrm{a}}$ \\
\hline
\end{tabular}

Values were expressed as mean \pm SEM and considered significant at $\mathrm{p}<0.05$. Values with different superscript along the same row are significantly different (Sample size, 5)

\subsubsection{Effects of $C$. milleni on the live function of Rats}

The liver function markers of rats fed with C. milleni seed and pulp are showed in Table 3. Aspartate Amino Transferase (AST) activity increased significantly $(\mathrm{p}<0.05)$ in the groups fed with the defatted seed and seed, while no significant difference $(\mathrm{p}>0.05)$ was observed between the control and group fed with pulp. No significant difference was observed in the
Alanine Amino Transferase (ALT) and Gamma Glutamyl Transferase (GGT) activities across the groups.

\subsubsection{Effects of $C$. milleni on the Renal function of Rats}

Figure $2 \mathrm{a}$ and $\mathrm{b}$ represented the creatinine and urea concentration respectively of rats fed with $C$. milleni and the commercial diet. Highest creatinine concentration was observed in the control group. Comparison between the control 
and groups fed with pulp and seed of $C$. milleni showed no significant difference $(\mathrm{p}<0.05)$. However, significant decrease was observed in the creatinine concentration of the group fed with the defatted seed. Urea on the other hand decreased significantly $(p<0.05)$ in the group fed with seed of $C$. milleni while no significant difference $(\mathrm{p}>0.05)$ was observed across the other groups.

\subsubsection{Effects of $C$. milleni on the histology of liver and kidney of rats}

3.1.4.1. Effects of C. milleni on the liver histology of rats

Plate $3 a$ and $b$ represent the photomicrograph of haematoxylin and eosin $(\mathrm{H}$ and E) stained liver section of rats in the control and treatment groups at $100 \mathrm{um}$ and $50 \mathrm{um}$ magnifications respectively. The representative photomicrograph showed the portal triad (PT), hepatic vein (HV), hepatic artery (HA), hepatic duct (HD), bile duct (BD) and the well distributed hepatocytes $(\mathrm{H})$. Observed in the photomicrograph included milddegenerative changes that can be termed as necrosis, some mild fibrosis and hemorrhage characterized by the presences of infiltrated red hemorrhagic and inflammatory cells (Group B-D). Also observed is a distortion (well defined dilation in the portal triad) in the walls of the blood vessels (red arrow), pyknotic hepatocytes and signs of inflammation (red arrow) is seen more especially in the group fed with C. milleni seed powder (group D). Group A on the other hand showed normal morphological presentation with an array of well outlined hepatocytes as well as the portal triad system.

3.1.4.2 Effects of C. milleni on the kidney histology of rats

The representative photomicrograph of $\mathrm{H}$ and $E$ stained section of the kidney of rats across the treatment and the control groups are presented in plate $4 a$ and $b$. Demonstrated across the study groups is the Renal Corpuscles (RC), Renal glomeruli (G), Macula densa (MD), Distal and Proximal (DCT \& PCT) convoluted tubules (renal tubules RT) and the bowman's capsule (BC). The red arrows indicate areas with marked pathomorphological changes.

The collagen (type IV) of the basement membrane outlines the glomerular capillaries. The collagen of the parietal layer (PL) of Bowman's capsule (BC) and the basal membrane (BM) of a distal tubule are observable from the photomicrographs. Marked degenerative changes characterized with fibrosis and hemorrhage (red arrows) showing varying degrees of renal injury evidenced by focal sclerosis of the glomerulus, widening of the Bowman's space and hyper-cellularity and complete collapse of the glomerulus. There is hyaline arteriolosclerosis, interstitial fibrosis, interstitial inflammation, as well as acute tubular necrosis are all observed in a mild to severe degree in treated group B-D relative to group A that appears normal. Features are consistent with chronic glomerulonephritis and or glomerulosclerosis. (Red arrows). 


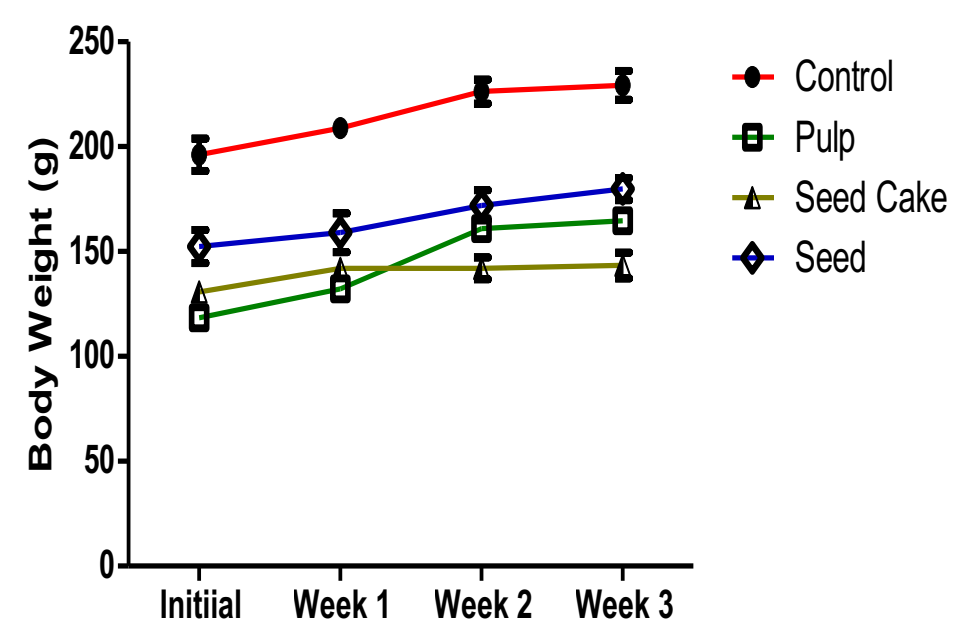

Figure 1. Weekly total body weight of Rats fed with C. milleni Values were expressed as mean \pm SEM

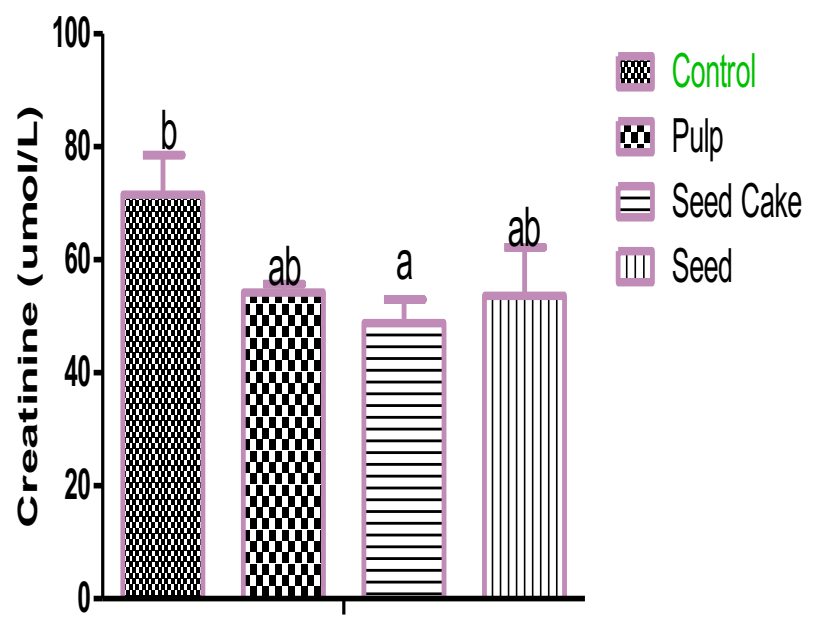

Figure 2 a, Serum creatinine concentration in Rats fed with C. milleni

Values were expressed as mean \pm SEM and considered significant at $\mathrm{p}<0.05$. Values with different superscript are significantly different 


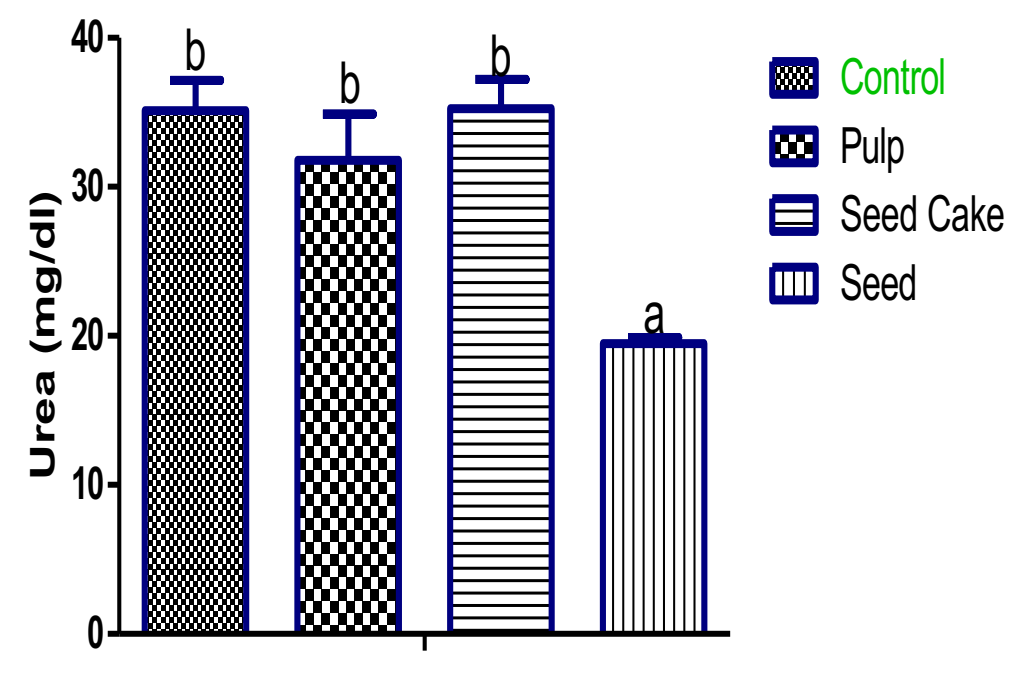

Figure 2b, Serum Urea concentration in Rats fed with C. milleni

Values were expressed as mean \pm SEM and considered significant at $\mathrm{p}<0.05$. Values with different superscript are significantly different
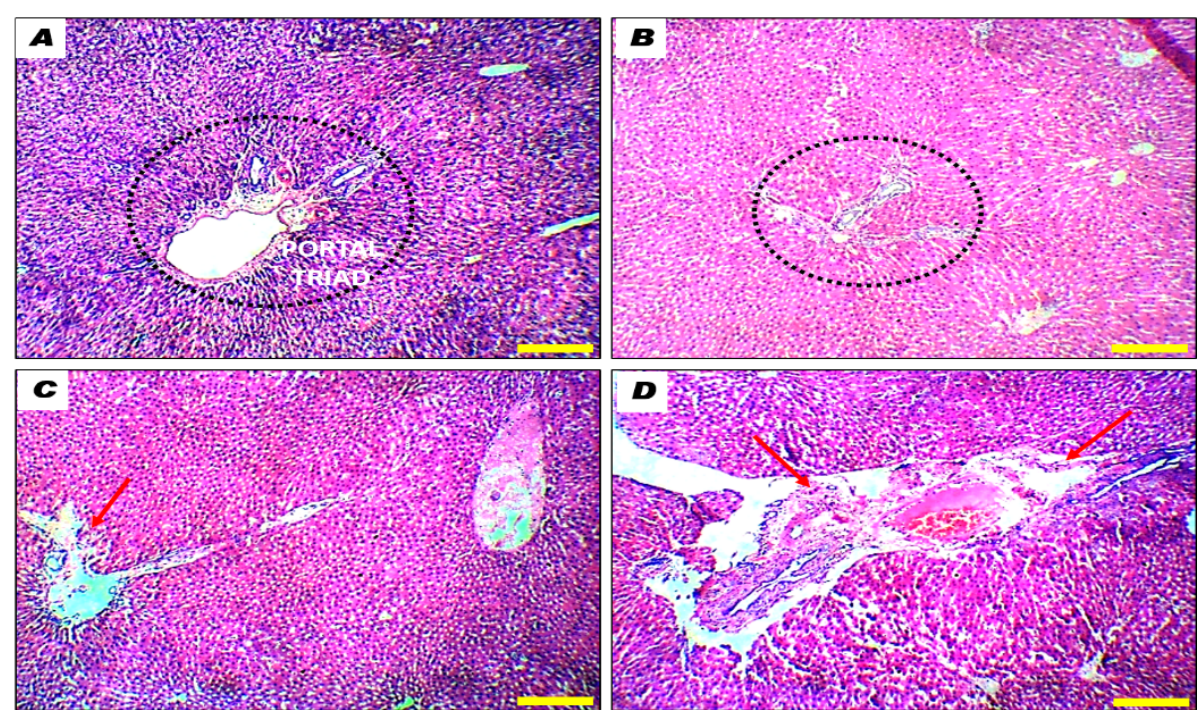

Plate 3a, Photomicrographs of the panoramic views of liver general micromorphological presentations in Adult Wistar rats across the study groups. Hematoxylin and Eosin stain (scale bar 100um). 

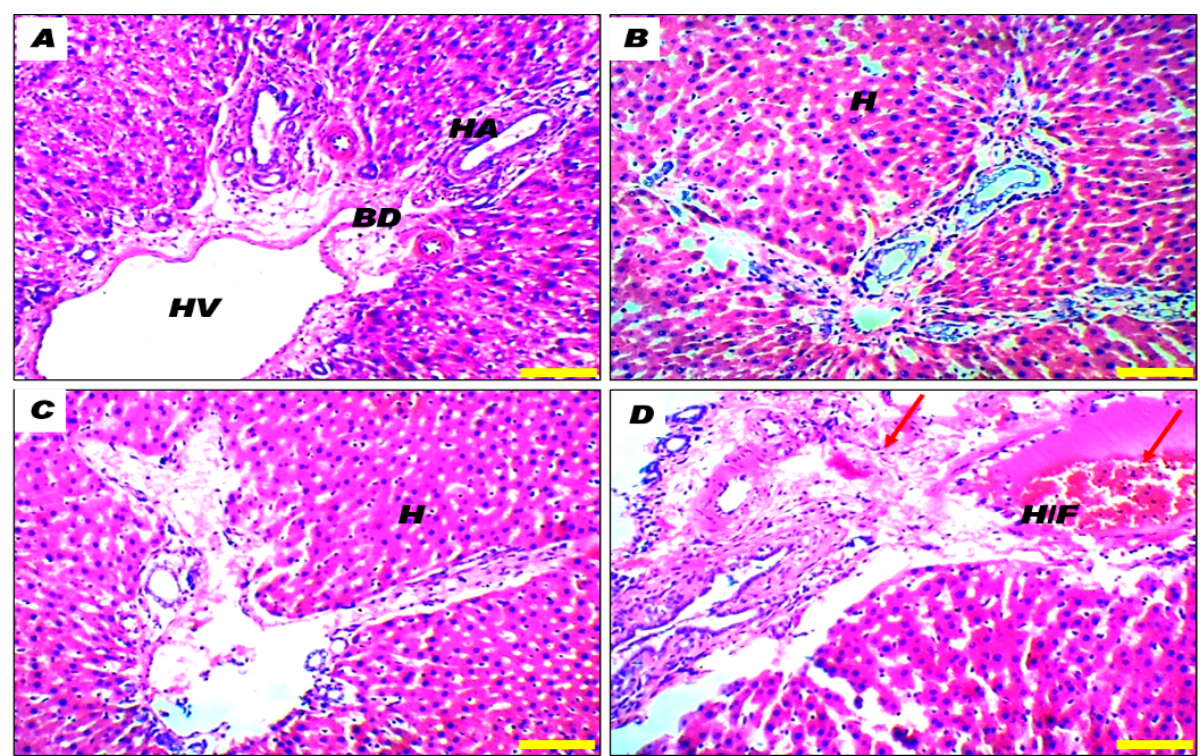

Plate 3b, Photomicrographs of liver general micromorphological presentations in Adult Wistar rats across the study groups. Hematoxylin and Eosin stain (scale bar 50um).

Key
A, Control group
$\mathrm{B}$, Group fed with the pulp of $C$. milleni
C, Group fed with the defatted seed of $C$. milleni
$\mathrm{D}$, Group fed with the seed of C. milleni
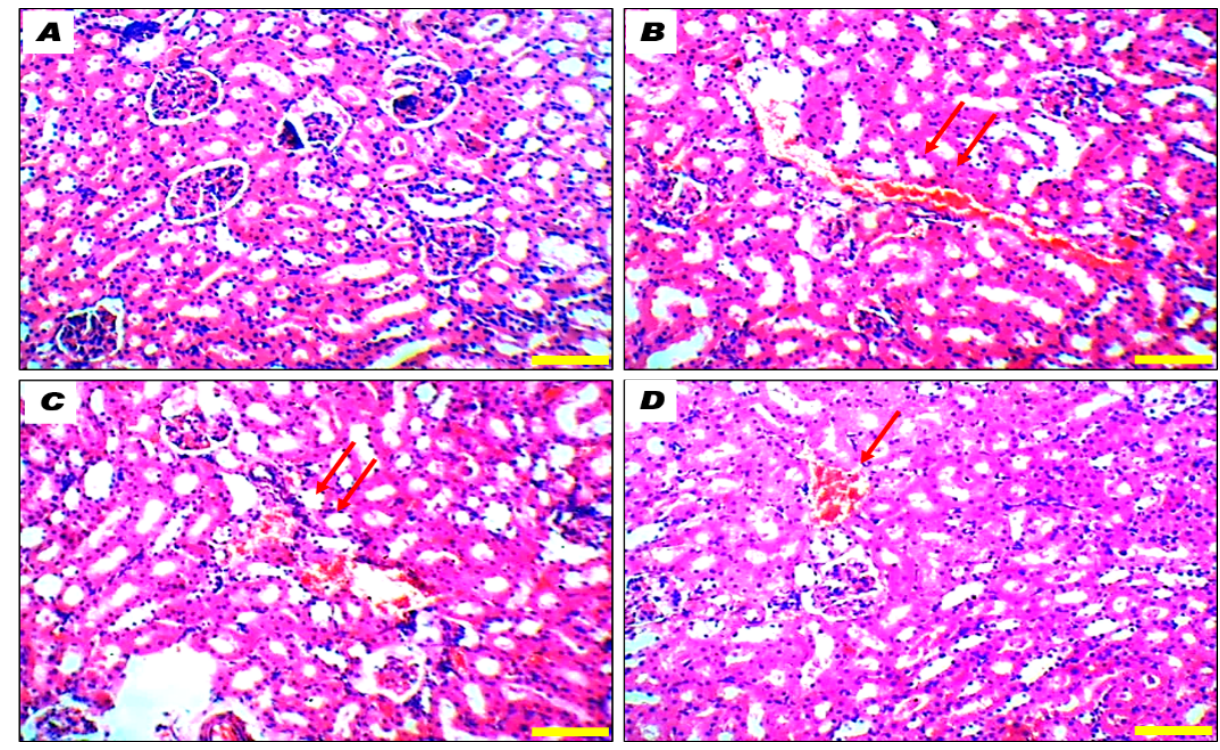

Plate 4a, Photomicrographs of the renal cortex showing panoramic views of Kidney general micromorphological presentations in Adult Wistar rats across the study groups. Hematoxylin and Eosin stain (scale bar 100um). 


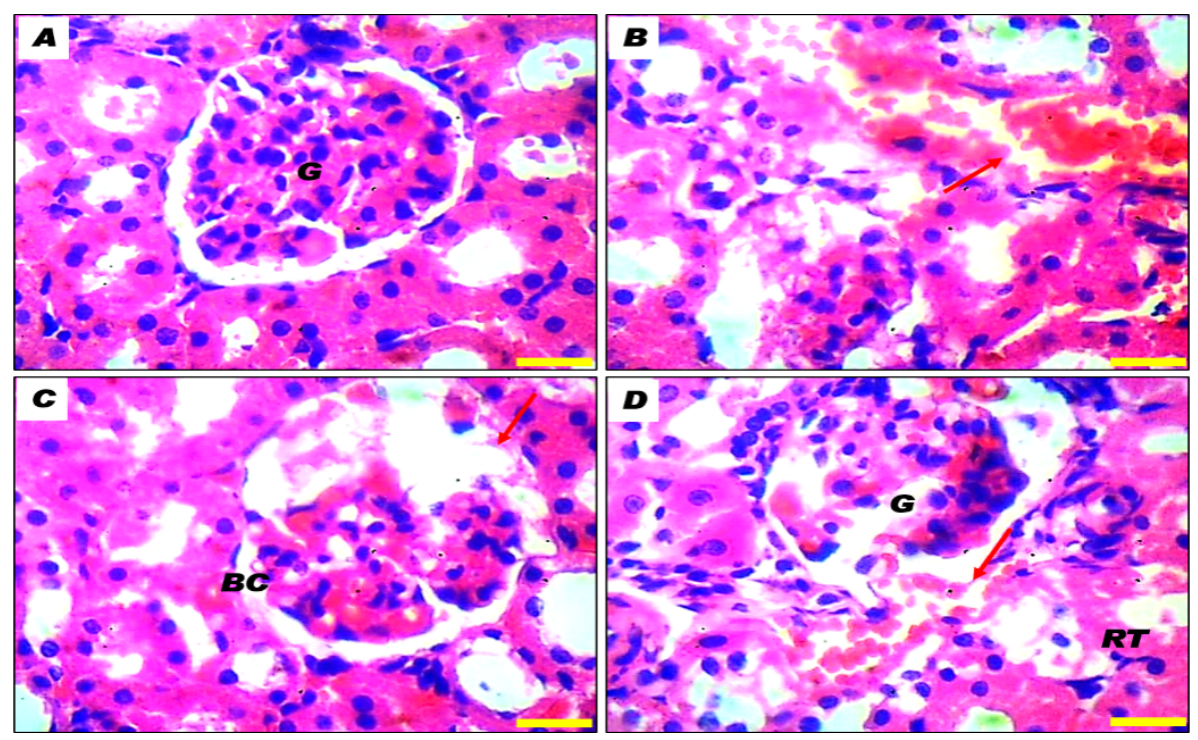

Plate $4 \mathbf{b}$, Photomicrographs of the renal cortex showing magnified views of Kidney general micromorphological presentations in Adult Wistar rats across the study groups. Hematoxylin and Eosin stain (scale bar 50um).

Key
A, Control group
$\mathrm{B}$, Group fed with the pulp of $C$. milleni
C, Group fed with the defatted seed of $C$. milleni
D, Group fed with the seed of C. milleni

\subsection{Discussions}

Cola millenii is an important plant of the transitional forest of Southern Nigeria (Ubon et al., 2008). The current interest of various experiment on the plant is owned to its many nutritional potentials (Borokini et al., 2014; Ibironke et al., 2013; Odugbemi, 2006). Data in the literature presents conflicting evidences as regards the nutritional risk of consuming $C$. millenii as food. Therefore, this present study assessed the health risk of consuming $C$. millenii seed and pulp in Albino rats. In this study, no death was observed among the experimental groups and the animals gained weight normally throughout the period of study. Therefore, feeding of the animals with $C$. millenii had no lethal effects as well as negative impact on the growth, food and water intake of the experimental animals.

Liver, which is the organ responsible for metabolism of most xenobiotics, is susceptible to chemical injury (Hodgson et al., 1988). Kidney on the other hand functions in getting rid

of the waste materials, which are either ingested or produced by detoxification process of the liver (Olorunnisola et al., 2019). Therefore, accumulation of these toxic metabolites or chemicals predisposes them to damage (Arthur and John, 2000). In this study, the toxic effect of C. milleni seed and pulp was assessed in the liver and kidney of rats.

Hence, the biochemical parameters monitored are useful indices for the assessment of liver and renal toxicity. It included the Asparatate Amino Transferase (AST), Alanine Amino Transferase (ALT), Gamma Glutamyl Transferase (GGT), creatinine, and urea.

AST, ALT and GGT enzymes are mainly localized in the liver and are released into circulation upon damage to the hepatic cells. Therefore, increase in their serum activity is usually an indication of damage to the liver cells and their concentration could reflect the extent of hepatotoxicity (Olorunnisola et al., 2019). Observation in this study i.e. increased observed in the AST activity of the group fed with the 
defatted seed and whole seed might reflect the toxic nature of $C$. millenii seed.

The histopathological studies on the liver further substantiate the result of the biochemical studies. The mild degenerative changes observed in the group fed with the seed of $C$. millenii are a reflection that the oil of C. mileni is toxic to the liver. Ogbeh et al. (2018) previously recorded the high acidity of $C$. millenii oil. According to the study, C. millenii had acid value far above the recommended for cooking oil and the value established by the Ministry of Public Health for various types of edible fats and oils. The results in this study also support the report of Itoandon et al. (2016) who reported potential toxicity of leaf extracts of $C$. milleni.

In the monitoring of renal function, urea and creatinine concentration can give insight to the effects of the plant sample on the tubular and glomerular functions of the kidney (Ukwuani $e t$ al., 2012). Therefore, high serum urea and creatinine level may be a pointer of renal failure (Hodgson et al., 1988). Furthermore, removal of creatinine from plasma is achieved during glomerular filtration process and excreted in the urine. However, when the plasma level increases above normal, creatinine could also be excreted through the tubules. The implication is that the serum creatinine level in renal disease generally does not increase until the renal function is substantially impaired (Faulkneret al.,, 1982).

Observations in this study substantiate the claim as no distortion was observed in the renal excretion of creatinine and urea whereas, histological studies revealed mild damage in the renal architecture.

Anti-nutritional factors in plants have been reported to cause modification in biochemical processes of the body. For instance, tannin was reported to reduce protein digestibility consequently reduce amino acid bioavailability (Aletor, 1993; Carnovale et al., 1991; Chai and Liebman, 2004). In this study, decreased serum urea concentration, which is an excretory product of protein digestion observed in the group fed with the seed, relative to the control group might be a reflection of decreased amino acid bioavailability rather than renal protection.

\section{Conclusions}

The result of this study showed that $C$. millenii seed might be slightly toxic to the liver and kidney. The study also revealed that the oil of the seed might have contributed to this toxicity in rats.

\section{References}

Adeniyi, B.A., Groove, M.J., Gangadharam, P.R.J. (2004) In vitro anti-mycobacterial activities of tree species on cola plant extacts (Sterculiaceae). Phytotherapy Research 18, 414-418.

Aletor, V.A. (1993) Allelochemicals in plant foods and feeding Stuffs. Part I. Nutritional, Biochemical and Physiopathological aspects in animal production. Vetinary Human Toxicology, 35, 57-67.

Anhwange, B.A., Ajibola, V.O., Oniye, S.J. (2004) Chemical studies of the seed of Moringa oleifera (Lam) and Deuterium microcarpum (Guill and Sperr). Journal of Biological Science 4,711-715.

Arthur, C.G., John, E.H. Textbook of medical physiology. Edition 10, Philadelphia, W.B. Sounders. 2000;279-281.

Bello MO, Falade OS, Adewusi SRA, Olawore NO. 2008. Studies on the chemical compositions and antinutrients of some lesser known Nigeria fruits, African Journal of Biotechnology, 7(21), 3972-3979

Borokini, F.B., Abitogun, A., Olumayede, E.G. (2014) Nutritional, antinitritional and antimicrobial activities of Seed and Pulp of Cola millenii. IOSR Journal of Applied Chemistry 7,113-118.

Carnovale, E., Marletta, L., Maeconi, E., Brosio, E. (1991) Nutritional and hydration properties in cowpea, cowpea genetics resources IITA, Ibadan, 111-118.

Chai, W., Liebman, M. (2004) Assessment of oxalate absorbtion from almonds and black beans with and without the use of an extrinsic label. Journal Urol 172,953-957. 
Deanna, M.M. (2019) A Review of the Science of Colorful, Plant-Based Food and Practical Strategies for "Eating the Rainbow" Hindawi Journal of Nutrition and Metabolism, 2125070,19.

Datta, P.K., Tukaramrao, D.B., Naidu, A. (2011) Safety Evaluation studies on Garden cress (Lepidium sativum L.) seeds in Wistar rats. International Journal of Applied Research in Natural Products 4, 37-43.

Faulkner, W.R., King, J.W., Norbert, W. T. (Ed). (1982) Renal function. In, Fundamentals of Clinical Chemistry. USA, WB Sounder Company. 975-978, 994-995.

Fawcett, J.K., Scott, J.E. (1960) A rapid method for the Determination of Urea. Journal of Clinical Chemistry 13,156

Giwa, O.E., Onileke, F.O., Adesina, I.A., Adebote, V.T. (2012) Phytochemical, and antimicrobial properties of seed and pulp of monkey cola (Cola millenii) on some selected clinical and food borne isolate. International Journal of Applied Biology and Pharmaceutical Technology 3, 390-400.

Hodgson, E., Mailman, R.B., Chambers, J.E. Macmillan dictionary of toxicology. London, The Macmillan Press; 31, 62, 89, 100, 164, 186-218 and 322; 1988.

Ibironke, A.A., Olusola, O.O. (2013) Phytochemical analysis and mineral element composition of ten medicinal plant seeds from South-West Nigeria. New York Science Journal 6, 22-28.

Itoandon, E.E., Nwachukwu, V.A., Erukainure, O.L., Lasore, O.O., Nwagala, P.N. (2016) Cola millenii leaf ethyl acetate extract, Fourier Transform Infrared (FTIR) Spectroscopy; Modulatory effect on serum indices and redox biomarkers. European Pharmacological Journal LXIII, (2), 7-11.

Odugbemi, T. (2006) Outlines and pictures of medicinal plants from Nigeria. University of Lagos Press. 2006,158.

Ogbeh, E., Gimba, C.E., Nuhu, A.A., Abechi, S.E., Iyun, O.R.A. (2018). Extraction and Characterization of Cola millenii K. Schum (Monkey Cola) Seed Oil, Optimization
Using Full Factorial Design of Experiment. Nigerian Journal of Pharmaceutical and Applied Science Research, 7, 1-6.

Olorunnisola, O.S., Adetutu, A., Owoade, A.O., Ajayi, F.A., Adegbola, P. (2019) Acute and Sub-acute Toxicity Assessment of Euphorbia lateriflora (Schum and Thonn) in Wistar Albino Rats. European Journal of Medicinal Plants 29, 1-10.

Orisakeye, O.T., Ojo, A.A. (2013) Antimicrobial and antioxidant evaluation of various parts of Cola millenii K. Schum plant. African Journal of Pharmacy and Pharmacology 7, 3019-3025.

Oyemitan, I.A., Kolawole, F., Abass, L., Oyedeji,A.O. (2016) Neuropharmacological activities of ethanolic extract of Cola millenii Dried Leaf in Rats. European Journal of Medicinal Plants 16, 1-12.

Pearse, A.E. (1985) Histochemistry theoritical and applied analytical technology Edinburgh, Churchill-Livingstone 10121026.

Suzanne, J.P.L., Lluis, S.M., Patrick, C., Ivonne, M.C.M. (2011) Safety assessment of plant food supplements (PFS). Food Function (2), 760.

Szasz, G. (1976). Clinical chemistry, 22, 205.

Tietz, N.W. (Hrsg.). (1995) Clinical guide to laboratory tests, 3. Auflage. Philadelphia, PA, WB Saunders, 1995,20-21, 76

Ubon, J.A., Akpanabiatu, M.I., Akpanyung, E.O., Ufot, U.F. (2017) Effects of ethanolic extracts of Cola millenii K. Schum seed on biochemical and toxicological indices of male wistar albino rats, Journal of Pharmacognosy and Phytochemistry 6, 160166.

Ukwuani, A.N., Abubaka, G., Hassan, S.W., Agaie, B.M. (2012) Toxicological studies of hydromethanolic leaves extract of Grewia crenata. International Journal of Pharmaceutical Sciences and Drug Research. 4,245-249 


\section{Acknowledgement}

All Laboratory members of the Department

of Pure and Applied Chemistry and

Biochemistry Department, Ladoke Akintola University of Technology 